\title{
Surfactant Improves Gas Mixing and Alveolar Ventilation in Preterm Lambs ${ }^{1}$
}

\author{
KENNETH SANDBERG, KARL-ERIK EDBERG, WILLIAM BENTON, ANTS SILBERBERG, \\ MALGORZATA SLADEK, AND HÅKAN W. SUNDELL
}

Department of Pediatrics, Vanderbilt University School of Medicine, Nashville, Tennessee 37232

\begin{abstract}
Prophylactic treatment with ovine surfactant was evaluated in preterm lambs at risk for development of hyaline membrane disease. Eight mechanically ventilated newborn lambs were treated before delivery and 10 served as controls (gestational age 129-131 d). Lung mechanics, functional residual capacity, alveolar ventilation, efficiency of ventilation, and distribution of ventilation were tested using pressure, flow, and nitrogen elimination (nitrogen washout during $100 \%$ oxygen breathing) measurements in the endotracheal tube. The surfactant-treated animals showed significantly improved gas mixing efficiency in the lung with improved alveolar ventilation. Single exponential washout pattern dominated in both groups. Adequate functional residual capacity was established earlier after birth in the treated lambs than in the control animals. Lung mechanics in the treated group showed significant improvement in dynamic lung compliance. Surfactant treatment also improved gas exchange and reduced respirator pressure requirement. We speculate that the main functional effect of surfactant treatment in preterm lambs at risk to develop hyaline membrane disease is to maintain the patency of the peripheral airways in the lung, which improves diffusive gas mixing, alveolar ventilation, and gas exchange. The techniques used in this study should also be useful to evaluate lung function in preterm human infants after specific adaptation of the equipment size. (Pediatr Res 30: 181 189, 1991)
\end{abstract}

\section{Abbreviations}

$\mathrm{C}_{\mathrm{dyn}}$, dynamic lung compliance of the respiratory system FRC, functional residual capacity

HMD, hyaline membrane disease

$\mathrm{NC}$, nitrogen clearance

PEEP, positive end expiratory pressure

PIP, positive inspiratory pressure

$\dot{\mathrm{V}}_{\mathrm{A}}$, alveolar ventilation

$V_{D}$, dead space

$V_{\mathrm{T}}$, tidal volume

$V_{L} N_{2}$, expired nitrogen lung volume

ET, endotracheal tube

$\mathrm{FiO}_{2}$, fraction of inspired oxygen

$F$, ventilatory flow

There is extensive evidence from studies in animal models and in human infants with HMD that endotracheal instillation of

Received August 14, 1990; accepted April 12, 1991

Correspondence: Håkan W. Sundell, M.D., Vanderbilt University School of Medicine, Department of Pediatrics, Nashville, TN 37232-2585.

Supported by grants from the National Institutes of Health (HL 14214). K.-E.E. and K.S. were partly supported by the Swedish Medical Research Council (Project No. 5703).

989. exogenous surfactant improves lung function (1-8), clinical course, and outcome (9-11). It has also been suggested that prophylactic surfactant treatment before initiation of spontaneous or mechanical ventilation is the best way to prevent injury to distal conducting airways, i.e. respiratory bronchioles and alveolar ducts, which otherwise is one of the characteristics of $\operatorname{HMD}(12,13)$.

This study was designed to investigate the immediate effects of prophylactic treatment with natural ovine surfactant on several aspects of lung function in a surfactant-deficient lung. Instillation of surfactant into such a lung is expected to alter its properties and function. It can also be postulated that the impact of positive pressure ventilation on a surfactant-deficient versus a nondeficient lung is quite different due to different functional characteristics. An HMD lamb lung model was used to mimic the clinical situation of prophylactic surfactant treatment in preterm infants at risk to develop HMD. The technique used to measure lung function was designed to be noninvasive, not to interfere with ongoing mechanical ventilation, and to be useful in newborn infants with lung disease.

\section{MATERIALS AND METHODS}

Animal preparation. Eighteen lambs were delivered by cesarean section at a gestational age of 129 to $131 \mathrm{~d}$. Term gestational age is $147 \mathrm{~d}$. The cesarean section was performed during general anesthesia induced by i.v. barbiturates followed by halothane, nitrous oxide, and oxygen inhalation. The ewes were monitored with arterial blood pressure and repeated arterial blood gases during the procedure. A small incision was done in the wall of the uterus. The head and neck of the lamb were exposed, leaving the body in utero with intact placental circulation. A tracheotomy was performed, and an ET, size 5.5, was secured. Catheters were inserted into the pulmonary artery from a jugular vein $(5 \mathrm{Fr}$ Swan-Ganz) and into a carotid artery for pressure monitoring and blood gas sampling.

Eight lambs were given surfactant and 10 lambs served as controls. The median birth weight and range was $3.5 \mathrm{~kg}(2.9-4.0$ $\mathrm{kg})$ in the treatment group and $3.9 \mathrm{~kg}(3.0-5.3 \mathrm{~kg})$ in the control group. The median gestational age and range was $129 \mathrm{~d}$ (129$131 \mathrm{~d})$ in both groups.

The research protocol was approved by the Vanderbilt University Animal Care Committee.

Experimental protocol. Leaving the umbilical circulation intact, the lamb was weighed and was thereafter placed on the maternal abdomen under a heat lamp. Before initiation of mechanical ventilation, lambs in the treatment group were given an endotracheal instillation of natural ovine surfactant in normal saline in a dose of $100 \mathrm{mg}$ phospholipid/ $\mathrm{kg}$ body weight $(6 \mathrm{~mL} /$ $\mathrm{kg}$ ). The surfactant solution was mixed with fetal lung liquid in the airways by repeated withdrawals and instillations with a syringe. The surfactant had been isolated from lung lavage fluid from adult ewes by a centrifugation procedure (14). Minimum 
surface tension of this material, as determined with a pulsating bubble surfactometer (Electronetics Corp., Amherst, NY), was less than 10 dynes $/ \mathrm{cm}$ after $5 \mathrm{~min}$ pulsation at phospholipid concentrations of 7 to $32 \mathrm{mg} / \mathrm{mL}$. The lambs in the control group were given the same volume of normal saline.

Mechanical ventilation was started 10 to $15 \mathrm{~min}$ before delivery of the lamb. A time-cycled, pressure-limited infant ventilator (Baby Bird, Bird Corp., Palm Springs, CA) was used with $\mathrm{FiO}_{2}$ of 0.8 . The initial respiratory settings for all lambs were: PIP, 30 $\mathrm{cm} \mathrm{H}_{2} \mathrm{O}$; PEEP, $5 \mathrm{~cm} \mathrm{H} \mathrm{H}_{2} \mathrm{O}$; rate of 60 breaths/min; and inspiratory time of $0.4 \mathrm{~s}$. Later during the study, the respirator settings were adjusted according to arterial blood gases with the aim to keep $\mathrm{PO}_{2}$ between 6.7 and $10.6 \mathrm{kPa}(50$ and $80 \mathrm{~mm} \mathrm{Hg})$ and $\mathrm{PCO}_{2}$ between 4.7 and $6.7 \mathrm{kPa}(35$ and $50 \mathrm{~mm} \mathrm{Hg})$. Hypoxia was treated by increasing $\mathrm{FiO}_{2}$ or mean airway pressure. Hypercarbia was treated by increasing PIP or ventilator rate. $\mathrm{FiO}_{2}$ was increased to no more than 0.8 to make nitrogen washout tests possible. To avoid pneumothorax, PIP was kept as low as possible. It was, however, not always successful to ventilate the sickest lambs optimally to achieve $\mathrm{PCO}_{2}$ between 4.7 and $6.7 \mathrm{kPa}$ despite high respirator settings. Sodium bicarbonate was given to treat metabolic acidosis with a base deficit exceeding $10 \mathrm{mmol} / \mathrm{L}$.

After delivery, the lambs were dried and kept under a radiant heater. Body temperature was monitored by a rectal probe and was kept at 38.5 to $39.5^{\circ} \mathrm{C}$. After delivery, catheters were placed in the umbilical artery and tarsal vein. During the study, the lambs were sedated by continuous morphine i.v. infusion $(0.01$ $\mathrm{mg} / \mathrm{kg} / \mathrm{h}$ ) and were kept paralyzed with pancuronium bromide (Pavulon $0.1 \mathrm{mg} / \mathrm{kg}$ i.v., Organon Inc., West Orange, NY). A continuous i.v. infusion of $2 \mathrm{~mL} / \mathrm{kg} / \mathrm{h}$ of $5 \%$ dextrose in water was given.

Lung function tests, arterial blood gases, pulmonary and systemic artery pressures, heart rate, and airway pressure were measured every $30 \mathrm{~min}$. Oxygenation was calculated as arterioalveolar oxygen tension ratio, using a simplified formula (15) Blood sugar and hematocrit were checked hourly. Blood transfusions were given regularly to replace blood sampling losses.

The study was terminated at $6 \mathrm{~h}$ after delivery. Immediately after death, an autopsy was performed, and several lung tissue blocks were obtained and fixed in Gendre's fluid, dehydrated, embedded in Paraplast (Sherwood Medical Industries, St. Louis, $\mathrm{MO}$ ), and sectioned at $3 \mu \mathrm{m}$ for light microscopy. Sections were stained with hemotoxylin and eosin and were reviewed in a blinded fashion without identification of specific treatment group.

In this paper, only the results from the lung function measurements will be presented. Hemodynamic data and results of other postmortem studies will be presented separately.

Lung Function Measurements. The technique for measurement of lung function in this study has previously been evaluated and described in spontaneously breathing infants (16-18).

The first lung function study was performed immediately before delivery, before clamping the umbilical cord. After this, studies were performed every $30 \mathrm{~min}$ until $6 \mathrm{~h}$ of age or until pneumothorax or death occurred. Because pulmonary air leaks influence ventilatory flow measurement in the ET, lung function studies were not done after a pneumothorax was diagnosed. Pneumothorax was diagnosed by a sudden change in gas exchange and a sudden increase in pulmonary artery pressure, followed by puncture of the pleural space. One animal in the treatment group and six animals in the control group developed pneumothorax. Ventilatory flow was measured in the ET tube by a heated pneumotachograph (Hewlett-Packard, Andover, MA; no. 0) connected to a pressure transducer (model no. MP451-871, $\pm 2 \mathrm{~cm} \mathrm{H}_{2} \mathrm{O}$; Validyne Engineering Corp., Northridge, CA) and a carrier demodulator (model no. CO1914, Validyne Engineering Corp.). Airway pressure in relation to atmosphere pressure was measured in the proximal part of the ET tube by a pressure transducer (Validyne Engineering Corp.; model no.
MP45-28-871, $\pm 50 \mathrm{~cm} \mathrm{H}_{2} \mathrm{O}$ ) and a carrier demodulator. Before the study, ventilatory flow and pressure transducers with connected catheters and demodulators were tested and were found not to deviate in phase or amplitude up to $15 \mathrm{~Hz}$.

Nitrogen concentration in breathing air was measured continuously in the proximal part of the ET tube by means of a nitrogen analyzer (model no. 505 Nitrolyzer, Med Science Electronics, Inc., St. Louis, MO). The rise time of the nitrogen analyzer was $50 \mathrm{~ms}$. Four $\mathrm{mL} / \mathrm{min}$ of breathing air was suctioned by the Nitrolyzer. To perform a multiple breath nitrogen washout test, a separate respirator with the same pressure and frequency settings as the lamb's own respirator, but using $100 \%$ oxygen, was connected to the ET tube by a Y-connector. During an expiration, the respirators were suddenly switched by means of clamps, and a multiple breath nitrogen washout test was performed. The oxygen breathing continued until the end tidal nitrogen concentration was less than $2 \%$. At that time, the lamb was reconnected to the original respirator. The switch between the respirators was done momentarily without any loss of the desired airway pressure, which is important for the support of FRC during the measurement.

The lung function measurement started by sampling simultaneous ventilatory flow and pressure signals during approximately 20 breaths. This was immediately followed by the nitrogen washout test, where ventilatory flow and nitrogen signals were sampled simultaneously. The flow, pressure, and nitrogen signals were all sampled bedside into a portable computer unit (NEC, Portable Powermate; NEC Technology, Boxborough, MA) and a 12-bit analog/digital converter (model no. DT2801; Data Translation, Marlborough, MA) with a sample rate of $200 \mathrm{~Hz}$ for further calculations. $V_{D}$ in the $Y$-connector and the pneumotachograph connected to the ET tube was $7 \mathrm{~mL}$. Between the measurements, the equipment was disconnected from the airway.

Calculations Derived from Multiple Breath Nitrogen Washout Test. Detailed descriptions of the analysis of the nitrogen washout test have been published previously $(17,18)$.

$F R C$. The $\mathrm{V}_{\mathrm{L}} \mathrm{N}_{2}$ was calculated by integrating the product of the simultaneous ventilatory flow and nitrogen concentration signals during $100 \%$ oxygen breathing. FRC was calculated by dividing $\mathrm{V}_{\mathrm{L}} \mathrm{N}_{2}$ by the end tidal $\mathrm{N}_{2}$ concentration before the initiation of oxygen breathing. No correction was made for the elimination of tissue $\mathrm{N}_{2}$ during oxygen breathing.

$V_{D}$ and $\dot{V}_{A}$. By least square fit, a single exponential curve was adjusted to the nitrogen lung volume elimination curve. The curve can be described as $V_{L} N_{2}(n)=V_{L} N_{2}(0) e^{-a n}$, where $n$ is breath number, $\mathrm{V}_{\mathrm{L}} \mathrm{N}_{2}(\mathrm{n})$ is the nitrogen volume remaining in the lung after $n$ breaths, $V_{L} N_{2}(0)$ is the nitrogen volume in the lung before the elimination, and $\mathrm{e}^{-\mathrm{a}}$ is the dilution factor $(\mathrm{W})$ defined as $\mathrm{W}=\mathrm{FRC} /\left(\mathrm{FRC}+\mathrm{V}_{\mathrm{T}}-\mathrm{V}_{\mathrm{D}}\right) \cdot \mathrm{V}_{\mathrm{D}}$ can then be calculated when

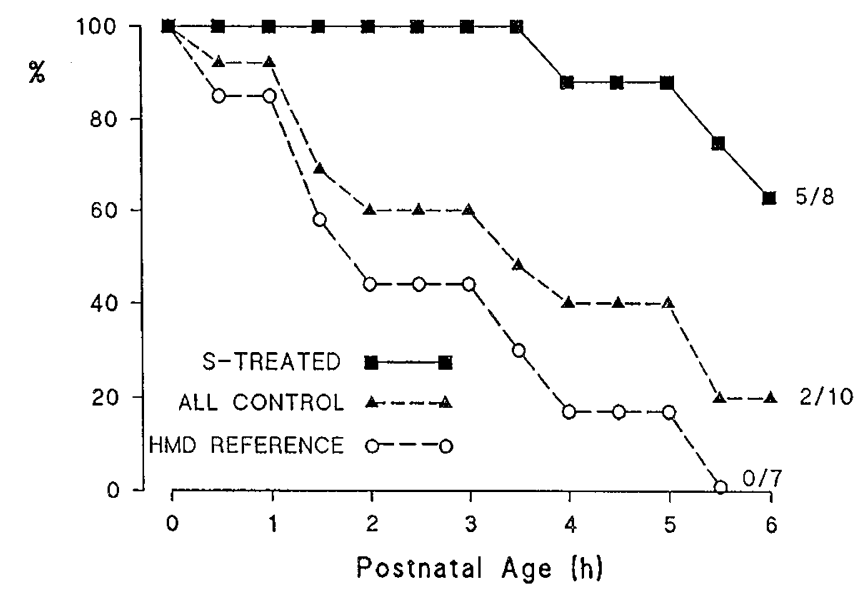

Fig. 1. Percentage of animals alive and without pneumothorax during the study. 


\section{A. PIP}

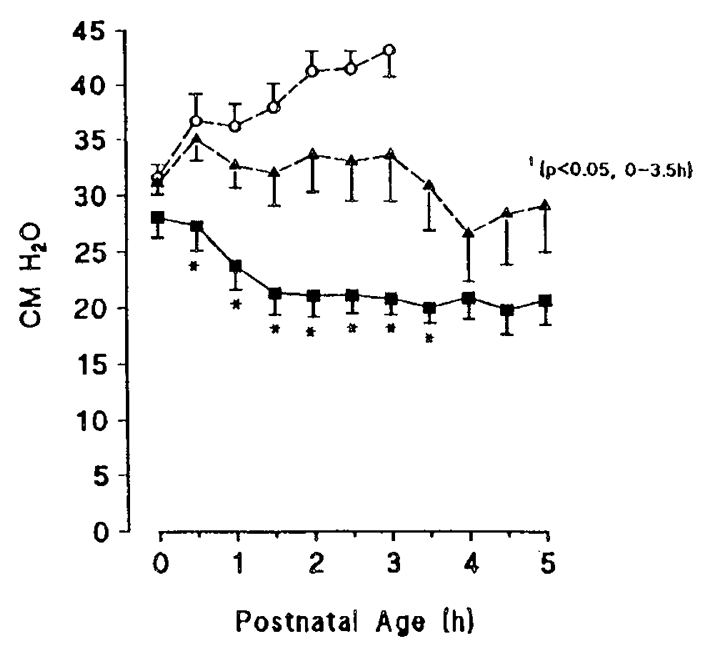

C. FREQUENCY

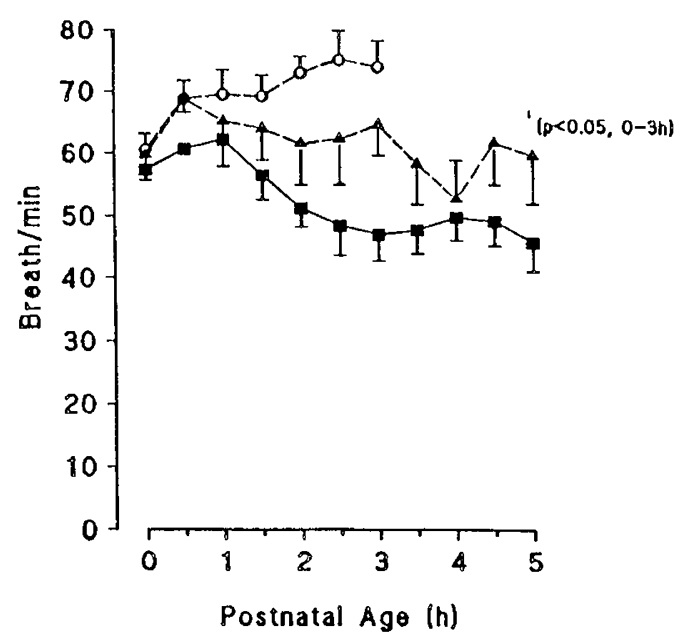

B. PEEP

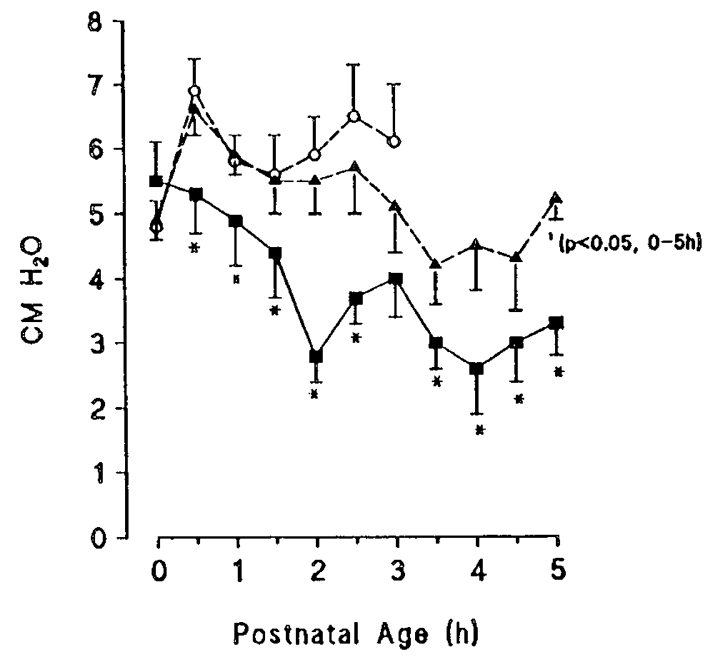

D. MAP

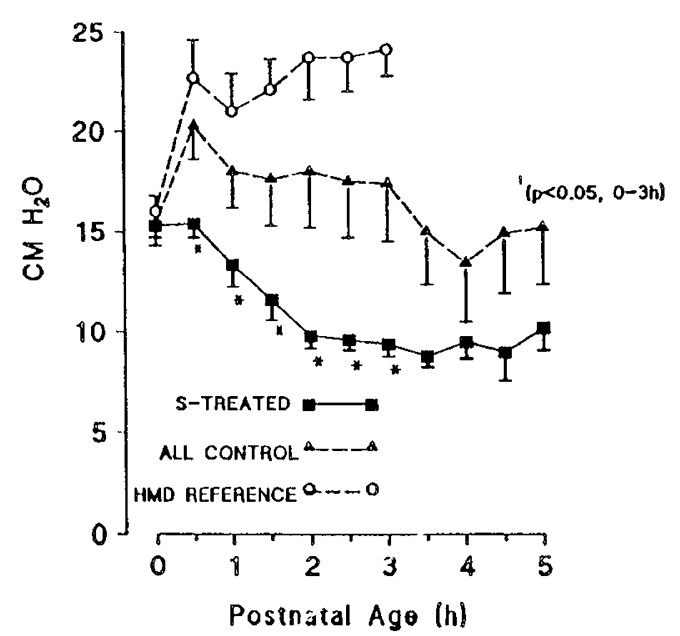

Fig. 2. Respirator settings during the study. $A$, PIP; $B$, PEEP; $C$, breathing frequency; $D$, mean airway pressure $(M A P)$. ${ }^{1}$, analysis of variance between treatment group and control group. ${ }^{*}$, significant difference $(p<0.05)$ at individual time points between treatment group and control animals.

FRC and $V_{T}$ are known entities. $\dot{V}_{A}=f\left(V_{T}-V_{D}\right)$, where $f$ is the breathing frequency.

Nitrogen elimination pattern (distribution of ventilation). Ideally, the nitrogen elimination pattern can be described as a single exponential curve with even distribution of ventilation $\left(\mathrm{V}_{\mathrm{L}} \mathrm{N}_{2}(\mathrm{n})=\mathrm{V}_{\mathrm{L}} \mathrm{N}_{2}(0) \mathrm{e}^{-\mathrm{an}}\right)$. If ideal conditions do not exist, the washout course is assumed to be described as the sum of two or more exponential components according to the following equation:

$$
\begin{aligned}
& \mathrm{V}_{\mathrm{L}} \mathrm{N}_{2}(\mathrm{n})=\mathrm{F}_{1} \cdot \mathrm{V}_{\mathrm{L}} \mathrm{N}_{2}(0) \cdot \mathrm{W}_{1}{ }^{\mathrm{n}}+\mathrm{F}_{2} \cdot \mathrm{V}_{\mathrm{L}} \mathrm{N}_{2}(0) \cdot \mathrm{W}_{2}{ }^{\mathrm{n}}+\ldots+\mathrm{F}_{\mathrm{k}} . \\
& \mathrm{V}_{\mathrm{L}} \mathrm{N}_{2}(0) \cdot \mathrm{W}_{\mathrm{k}}^{\mathrm{n}}
\end{aligned}
$$

where $\mathrm{V}_{\mathrm{L}} \mathrm{N}_{2}(0)=\mathrm{F}_{1} \cdot \mathrm{V}_{\mathrm{L}} \mathrm{N}_{2}(0)+\mathrm{F}_{2} \mathrm{~V}_{\mathrm{L}} \mathrm{N}_{2}(0)+\ldots+\mathrm{F}_{\mathrm{k}} \cdot \mathrm{V}_{\mathrm{L}} \mathrm{N}_{2}(0)$ and $F_{1}, F_{2} \ldots \ldots$ and $F_{k}$ are fractions of $V_{L} N_{2}(0) . W_{1}, W_{2} \ldots$ and $\mathrm{W}_{\mathrm{k}}$ are dilution factors for the different exponential components. The fitting of one or the sum of two or three exponential components to the original nitrogen volume elimination curve was done by using multiple linear regression, least square fit estimation, and the Z-transform. This allowed the curve fitting to be carried out in a linear representation. The statistically most significant number of exponential components was judged by $F$ test. Some of the washout curves could not be described satisfactorily by our lung model and were then assumed to contain a nonexponential component.

Ventilatory efficiency. The efficiency of the ventilatory system $(19,20)$ was calculated as an NC index. NC was defined as the ventilatory volume necessary to dilute the nitrogen lung volume from 90 to $10 \%$ of its total value, divided by the FRC $\left(\mathrm{nV}_{\mathrm{T}} /\right.$ FRC).

Calculation of Lung Mechanics. Lung model and parameter estimation. The mechanical properties of the respiratory system can be described in the following linear equation (21):

$$
\mathrm{P}(\mathrm{t})=1 / \mathrm{C} \int \mathrm{F}(\mathrm{t}) \mathrm{dt}+\mathrm{RF}(\mathrm{t})
$$

the applied pressure, $P$, from the ventilator at time $t$ is balanced by an elastic and resistive pressure component of the respiratory system. $\mathrm{F}$ is the ventilatory flow signal. In this model, the various regions of the pulmonary system are assigned to different functional compartments. A conducting airway with the resistance $R$ leads to an alveolar compartment with the compliance $C$.

The equation was used to model the measured ventilator pressure. The compliance and resistance parameters that mini- 


\section{A. VENTILATION/MIN}

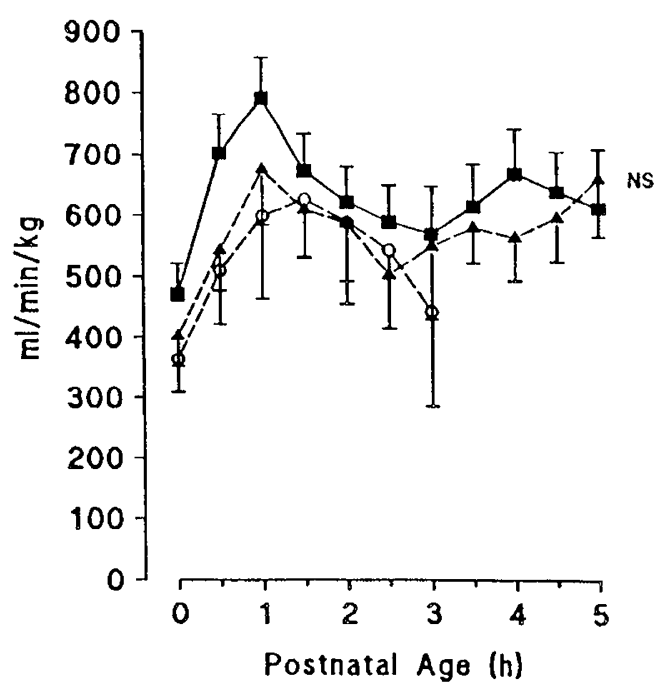

C. EFFECTIVE BREATH FRACTION

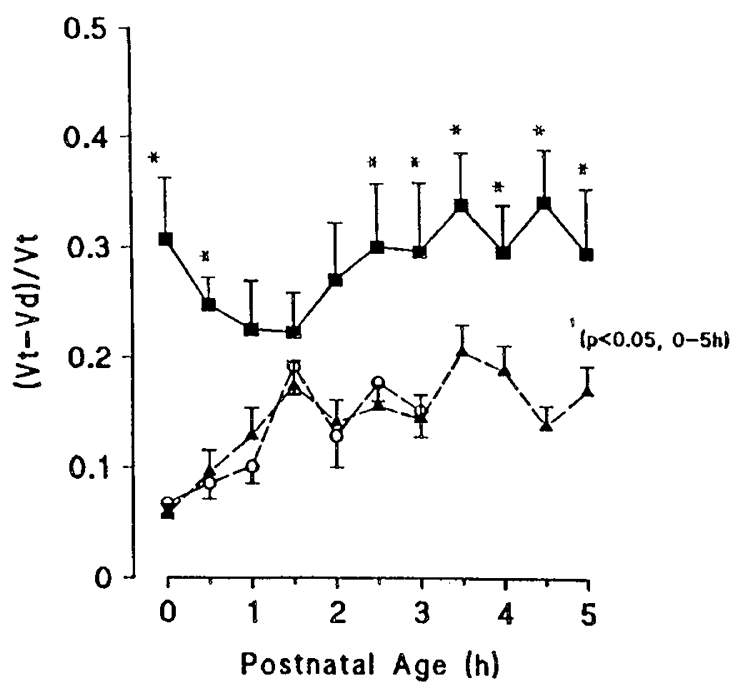

\section{B. TIDAL VOLUME}

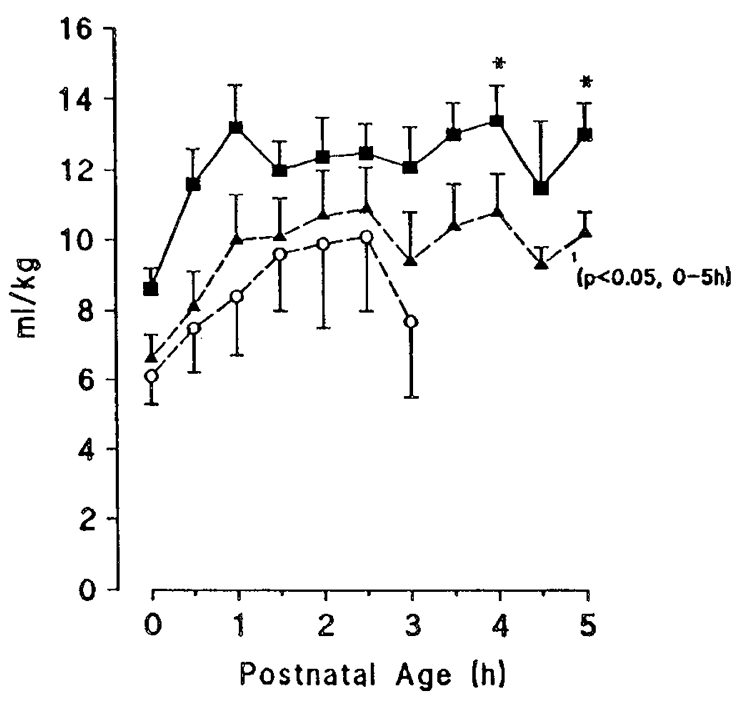

D. ALVEOLAR VENTILATION

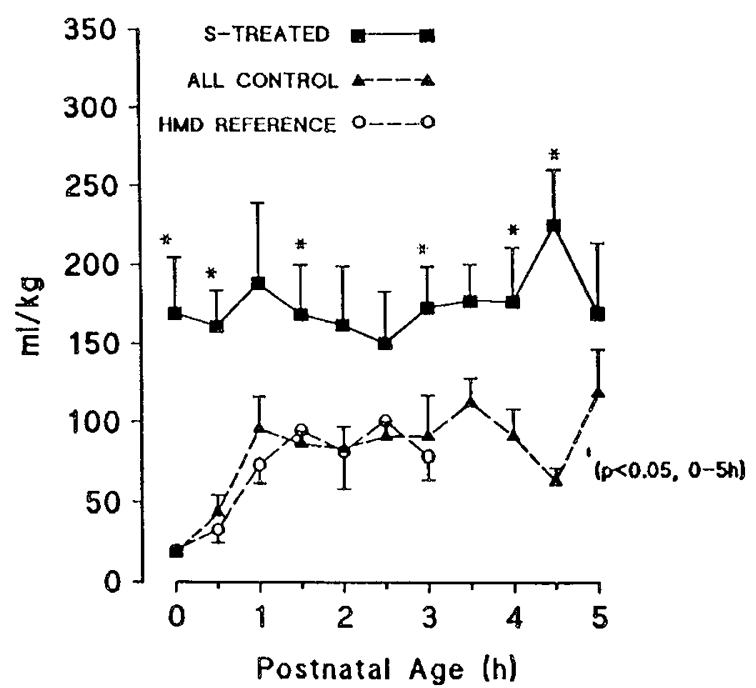

Fig. 3. Total ventilation per $\min (A), \mathrm{V}_{\mathrm{T}}(B)$, effective breath fraction $\left[\left(V_{t}-V_{d}\right) / V_{t}\right](C)$, and $\dot{\mathrm{V}}_{\mathrm{A}}(D)$ during the study. For statistical abbreviations, see legend for Figure 2.

mize the resulting mean-square error during an entire respiratory cycle were chosen (22). The average resistance and compliance values from five to 10 different respiratory cycles were used to represent the respiratory mechanics from one lung function study.

Statistics. In the data analysis, the principal comparison was done between the treatment group and all animals in the control group $(n=10)$.

In the control group, seven lambs developed histologically verified HMD. Inasmuch as there are limited data in the literature describing lung function in lambs with histologically verified HMD, the results from these animals $(n=7)$ are presented as an "HMD reference group." However, no statistical comparison was made between the reference group and the treatment group; statistical comparison was made only between the treatment group and the complete control group, as was the design of the study.

Repeated measures analysis of variance was used to assess whether there was an overall difference between the groups. For the comparison between the surfactant-treated group and the control group, the analysis was based on all animals alive and without pneumothorax at $5 \mathrm{~h}$. The analyses included 11 distinct time points. For differences at individual time points, a standard $t$ test was used. Because this led to multiple statistical tests, we have assessed the probability of observing statistically significant results for a single variable based on the total number of 11 tests performed. This calculation is based on binomial distribution, used to model how likely we would be to observe a specified number of significant results or more, based on a 5\% probability that a single test would be significant by chance. This approach ignores any possible correlation between one test and another. For 11 tests, it is unlikely that we would observe three or more tests to be significant by chance $(0.0152)$. The data are presented as means \pm SEM

\section{RESULTS}

As presented in Figure 1, survival without pneumothorax was better in the surfactant-treated group compared with the control 
A. a/A $\mathrm{PO}_{2}$ RATIO

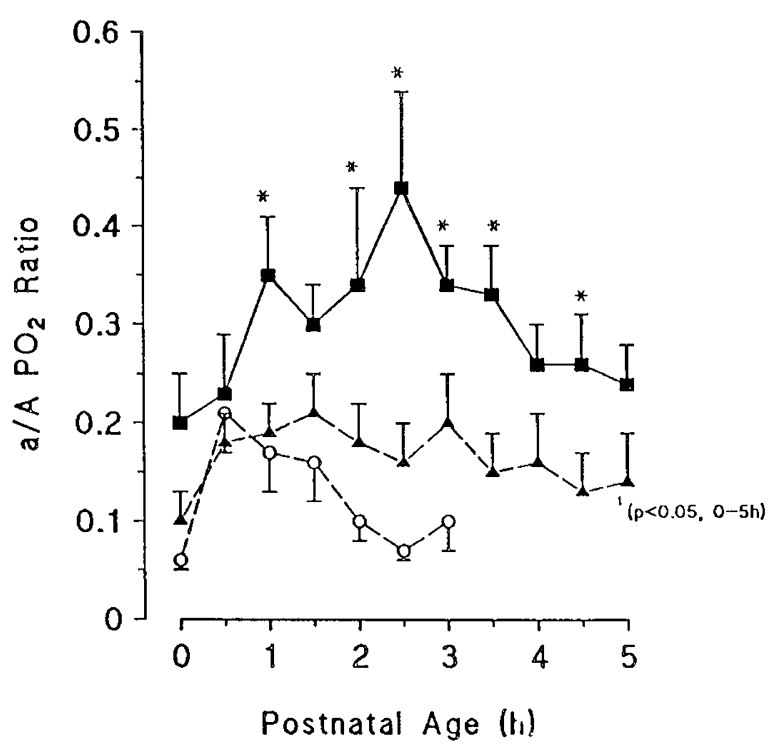

B. $\mathrm{PCO}_{2}$

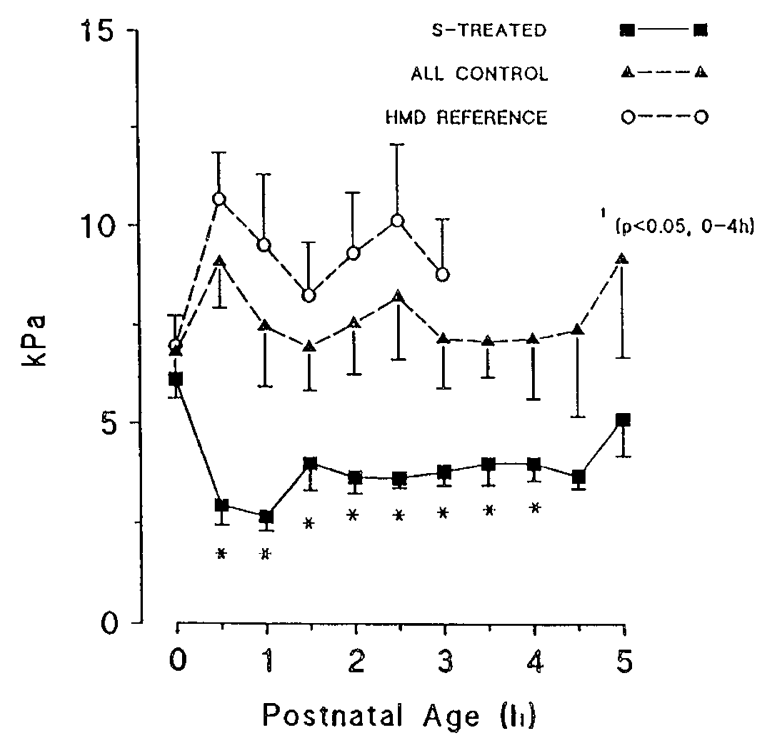

Fig. 4. Gas exchange during the study. $A$, arterio-alveolar oxygen tension ratio $\left(a / A P_{2} O_{2} R A T I O\right) ; B$, arterial $\mathrm{PCO}_{2}$. For statistical abbreviations, see legend for Figure 2.

group. In the treatment group, one animal developed pneumothorax at $5^{1 / 2} \mathrm{~h}$ of age. In the control group, six animals developed pneumothorax at different postnatal ages. Four of them developed pneumothorax before $2^{1 / 2} \mathrm{~h}$ of age. Most of the lambs in the control group died shortly after a pneumothorax was diagnosed. As a consequence, there were progressively fewer control animals during the study period, which makes statistical comparison at later time points difficult.

The required ventilator settings are presented in Figure 2. The treatment group needed significantly less PIP, PEEP, and respirator frequency compared with the control animals. The mean airway pressure consequently differed significantly between the groups.

Although the ventilator settings differed significantly, the achieved total ventilation per minute did not differ between the treatment group and the control group (Fig. $3 A$ ). $\mathrm{V}_{\mathrm{T}}$, however, was significantly higher in the surfactant-treated group (Fig. $3 B$ ).

The ratio between the effective part of the tidal breath and the $\mathrm{V}_{\mathrm{T}}\left[\left(\mathrm{V}_{\mathrm{T}}-\mathrm{V}_{\mathrm{D}}\right) / \mathrm{V}_{\mathrm{T}}\right]$ was significantly higher in the surfactanttreated animals (Fig. $3 C$ ). The $\dot{\mathrm{V}}_{\mathrm{A}}$ was also significantly higher in the treatment group (Fig. $3 D$ ).

The gas exchange is presented in Figure 4. The oxygenation, calculated as an arterio-alveolar oxygen tension ratio, was significantly better in the surfactant-treated animals, reaching its peak values at 2 to $3 \mathrm{~h}$ after delivery. After this, a deterioration in oxygenation could be observed. Arterial $\mathrm{PCO}_{2}$, reflecting the improved $\dot{V}_{A}$, was significantly lower in the treated animals.

Lung volume measurements are presented in Figure 5. There were significant differences in FRC between the groups only during the 1st hour after delivery. An adequate FRC was established rapidly after delivery in the surfactant-treated animals, whereas this was slowly achieved during the first 1 to $2 \mathrm{~h}$ after birth in the control group.

Mechanics of breathing of the respiratory system is presented in Figure 6 . The $\mathrm{C}_{\mathrm{dyn}}$ per $\mathrm{kg}$ body weight was significantly higher in the surfactant-treated group (Fig. $6 \mathrm{~A}$ ). Specific compliance $\left(\mathrm{C}_{\mathrm{dyn}} / \mathrm{FRC}\right)$ was lower in the control lambs after $1 \mathrm{~h}$ of age compared with the treatment group, but this difference was not statistically significant (Fig. $6 B$ ). Resistance in the respiratory system showed no significant difference between the groups, although there was a tendency toward lowering of the resistance during the study period.

Ventilatory efficiency, reflecting the efficiency of gas mixing in peripheral airways, was calculated as NC index and is presented in Figure 7. The surfactant-treated lambs showed significantly lower NC index compared with the control lambs, implying an improved gas mixing in distal airways.

In the analysis of the nitrogen elimination pattern (distribution of ventilation), one exponential washout pattern dominated in both the treatment and control group ( 76.3 versus $81.2 \%)$ (Table 1). There was no statistically significant difference in the nitrogen elimination pattern between the groups, and there was no change in the elimination pattern during the course of the study in either group.

Morphology. Lung appearance post-mortem. At autopsy, lungs from five of the control lambs appeared reddish-purple, poorly expanded, and liver-like, except for the upper lobes and part of the middle lobes in three of the lambs. The purple areas were estimated to constitute 80 to $100 \%$ of the total lung volume in these lambs. Subpleural blebs were present in two of the lambs. Three of the control lambs had lungs that were mostly pink and well expanded, and only 10 to $25 \%$ of these lungs appeared purple. Lungs from the surfactant-treated lambs were mostly pink and well expanded, but contained purple areas estimated to make up 0 to $15 \%$ of the lung volume. Subpleural blebs were seen in one lamb.

Pulmonary histology. Sections from right upper and lower lobes were evaluated qualitatively for presence of sloughing of epithelium in respiratory bronchioles and alveolar ducts, hyaline membrane formation in distal conducting airways, normal or reduced alveolar volume that would indicate atelectasis, air dissection, capillary and venous congestion, hemorrhage, and signs of pulmonary edema, e.g. wide interlobular connective tissue spaces, perivascular and/or periobronchial edema and lymphatic dilation. Based on the histologic review, the control lambs were divided into one group of seven lambs with HMD and one group of three lambs without HMD.

In the lambs classified as HMD, all showed extensive sloughing of the epithelium in respiratory bronchioles and alveolar ducts. Hyaline membrane formation was seen in all except one lamb, which died at $45 \mathrm{~min}$ after birth. A uniform and marked decrease in alveolar volume was seen in all of these lambs and perivascular-peribronchiolar air dissection was seen in six out of seven lambs. All lambs showed moderate to marked venous and capillary congestion and hemorrhage in the subpleural space, in 


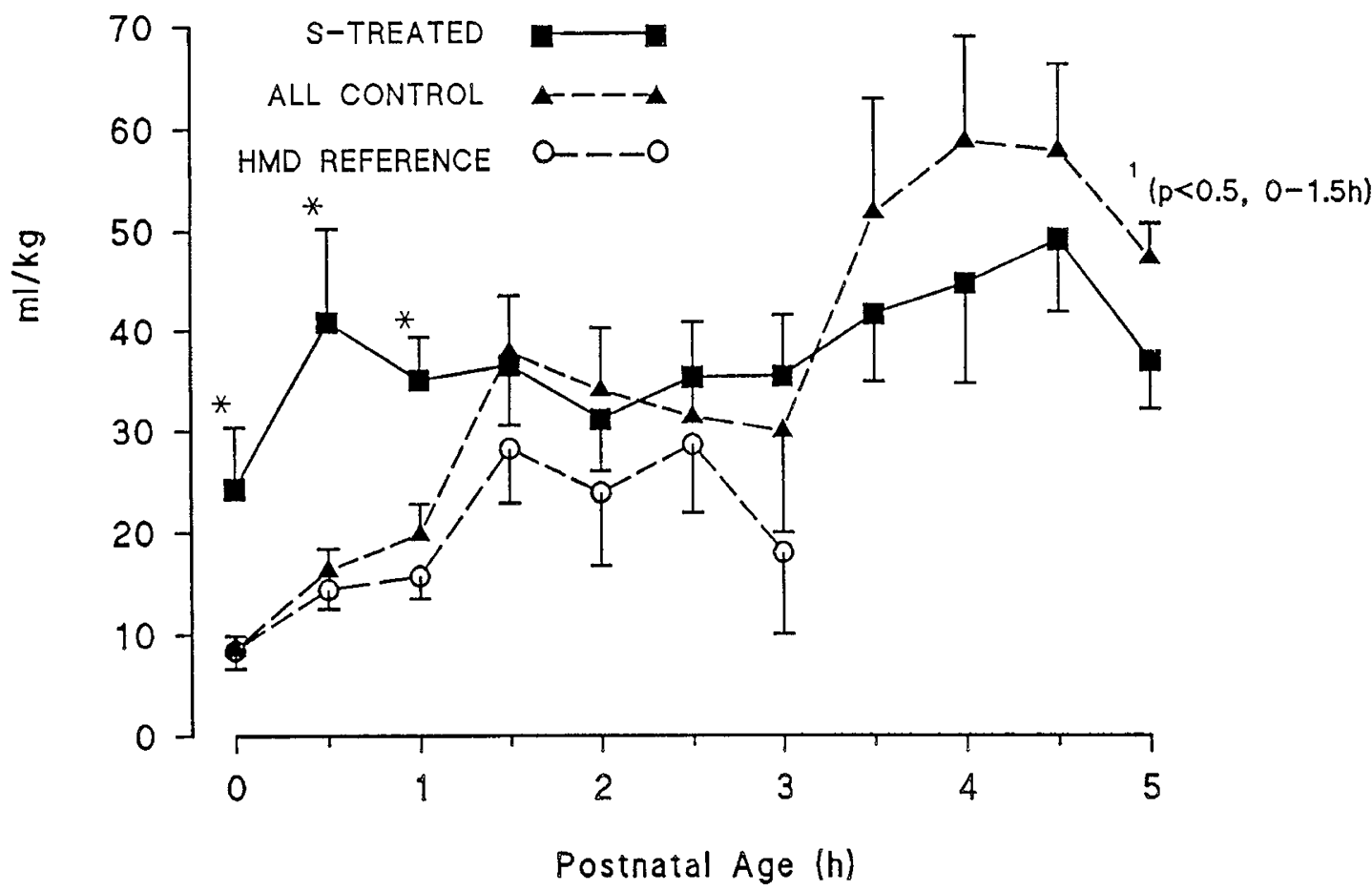

Fig. 5. FRC during the study. For statistical abbreviations, see legend for Figure 2.

tissue septa, or focally in alveoli. Pulmonary edema was present in all the lambs, as indicated by dilation of perivascular-peribronchial spaces and edema fluid in alveoli and distal conducting airways.

The three control lambs that did not develop HMD showed only a few epithelial sloughs, and no hyaline membranes were seen. The alveolar volume was generally good. Air dissection was seen in one of these lambs. All three lambs showed some capillary congestion, pulmonary edema, and hemorrhage. Widespread hemorrhage was the dominating histologic feature in one of these lambs.

There were no hyaline membranes identified in any of the surfactant-treated lambs and only a few scattered epithelial sloughs were seen in two of the eight lambs. The surfactanttreated lambs showed mostly good alveolar volume, although some areas of decreased volume were seen in all but one of the lambs. Air dissection, capillary congestion in areas with decreased alveolar volume and interstitial hemorrhage were present in three of these lambs. Pulmonary edema in the form of dilated tissue septa and perivascular-peribronchial spaces was seen in all of the treated lambs. Alveolar edema was only seen in scattered areas.

\section{DISCUSSION}

The objective of our study was to evaluate the immediate influence of natural lung surfactant treatment before delivery on the development of lung volume, ventilation, and efficiency of ventilation together with mechanics of breathing in preterm lambs at risk for development of HMD. The gestational age of the lambs in our study varied between 129 and $131 \mathrm{~d}$. At this age, it can be anticipated that the majority of the lambs will develop a respiratory disease with functional and histologic similarities to HMD in the preterm infant (23). In the present control group, seven of the 10 lambs had histologic signs of HMD, and three did not. Because there is a limited amount of data in the literature on lung function in lambs with histologically verified HMD, the results from these animals were analyzed separately and presented as an HMD reference group, but not statistically treated as a control group.

We observed significant differences in gas exchange and in the need for ventilatory support between surfactant-treated and untreated lambs. The surfactant-treated lambs required less respirator pressure, were better oxygenated, and had lower $\mathrm{PCO}_{2}$ (Fig. 4). This has also been found by other investigators $(3,5)$. Despite lower airway pressure, FRC in the surfactant-treated lambs was significantly higher only during the 1 st hour after delivery compared with the control animals (Fig. 5). Later during the study, no significant differences were found between the groups. Early establishment of an adequate FRC after surfactant treatment in preterm animals has been found by other investigators. Durand et al. (2), using an He-dilution "bag in the box" method, found significantly higher FRC already at 30 min of age in surfactanttreated animals. The difference in FRC persisted during their study up to $9 \mathrm{~h}$ after delivery. The difference between this study and our results could be explained by different use of PEEP level. Durand $e t$ al. used a constant PEEP during the whole study, whereas in our study the PEEP was increased in the control animals to optimize oxygenation. The importance of using a constant ventilator PEEP level during the study has been expressed by other investigators to avoid changes in the mechanical properties of the lung induced in itself by the variations in PEEP level (24). However, because we wanted to reflect the clinical situation, where changes in PEEP are used to improve gas exchange, no such limitations were instituted.

Studies of pressure-volume curves from surfactant-treated lungs have also shown significantly improved retention of gas at end expiration $(3,4,6,8)$. An immediate beneficial effect of surfactant on FRC has been shown by Lachmann et al. (6). They found a significant retention of gas in the lung already during the first breaths postpartum in surfactant-pretreated rabbits. In our postmortem histologic examinations of the lung tissue, we found improved alveolar air expansion after surfactant treatment, whereas severely decreased alveolar volume dominated in untreated lungs. This has also been found by previous investigators $(4,8)$. Absence of a significant difference in FRC between the groups after $1 \mathrm{~h}$ in the presence of decreased alveolar volume may indicate that the airways proximal to the alveoli were overexpanded due to high respiratory pressure in the control animals with HMD compared with the surfactant-treated lambs. Excessive expansion of alveolar ducts and respiratory bronchioles could lead to damage of the epithelium, sloughing, and hyaline 


\section{A. $\mathrm{C}_{\mathrm{dyn}} / \mathrm{Kg}$}

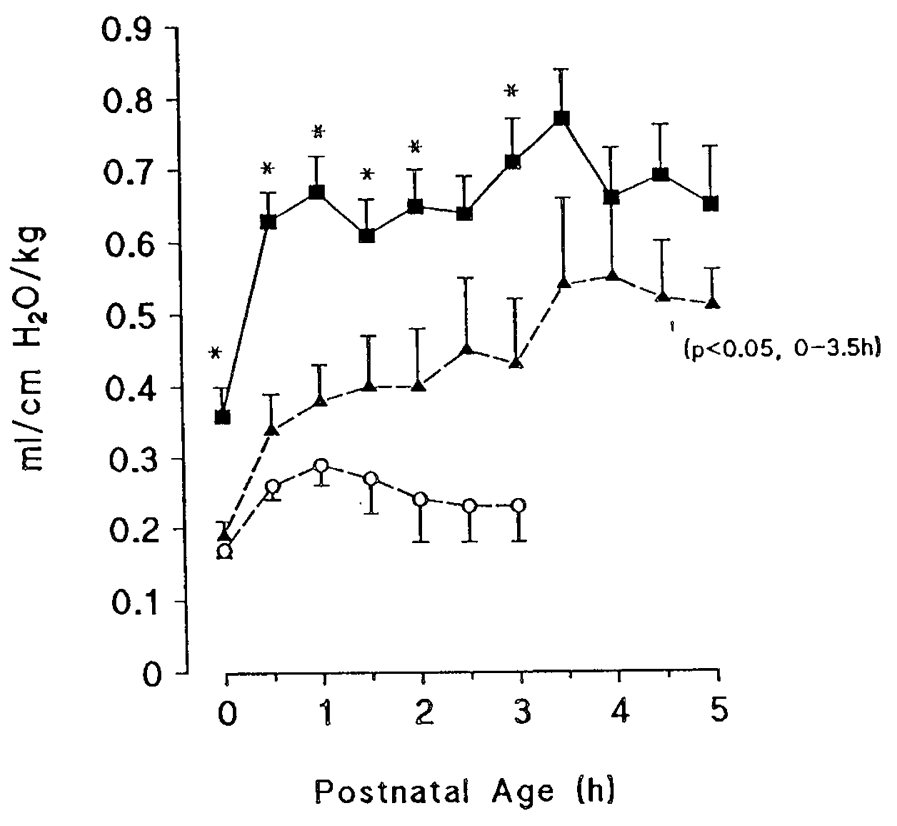

B. SPECIFIC COMPLIANCE

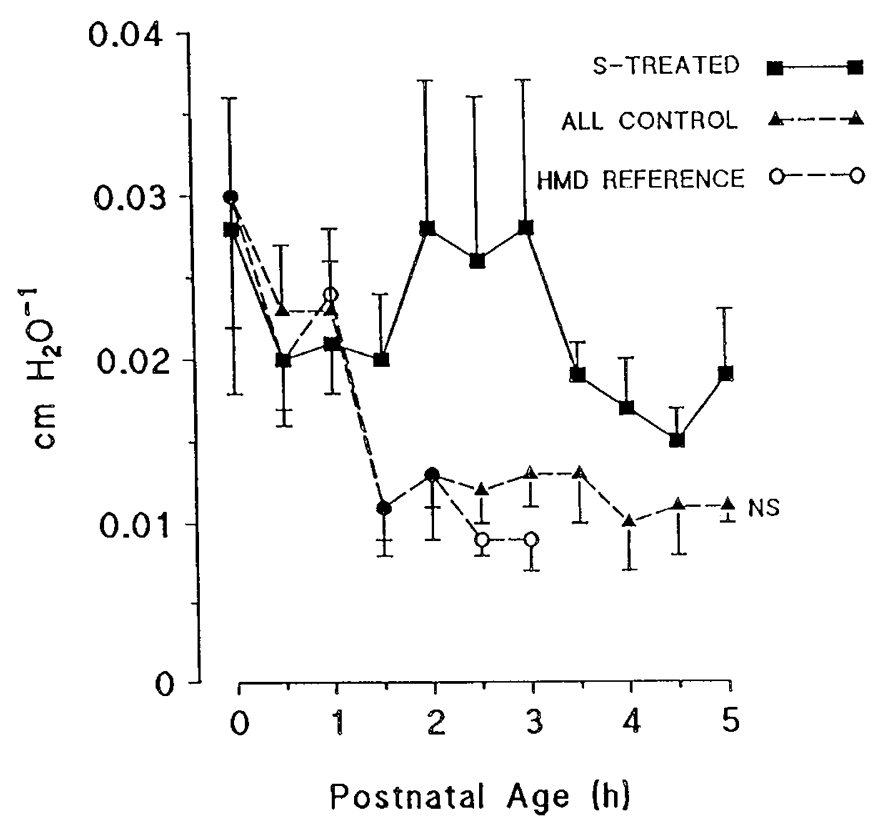

Fig. 6. $A, \mathrm{C}_{\mathrm{dyn}} / \mathrm{kg}$ body wt during the study. $B$, specific compliance $\left(C_{d y n} / F R C\right)$ during the study. For statistical abbreviations, see legend for Figure 2.

membrane formation. This could be followed by scarring with signs of obstructive lung disease during the recovery from HMD. Airway obstruction with an increase in resistance to ventilatory flow is also an important feature in the pathophysiology of bronchopulmonary dysplasia in infancy (25).

The functional goal in surfactant treatment should be to maintain patency of distal airways and alveoli so that gas mixing by diffusion is possible resulting in an adequate $\dot{V}_{A}$. During breathing, the inspired gas has to mix with the remaining alveolar gas in the lung. The more efficient this mixing is, the greater the part of the tidal breath that takes part in the mixing, the smaller the functional $V_{D}$ in the lung is. Both convective and diffusive forces are responsible for the gas mixing. According to previous investigators and lung model analyses, molecular diffusion is responsible for the main part of gas mixing between the inspired fresh air and the remaining alveolar gas $(26,27)$. Establishment of a semistationary front between inspired and alveolar gas at end inspiration is crucial for gas mixing by diffusive forces to be able to take place. In the lung periphery, the total cross-sectional area of the airways increases considerably, which means that the ventilatory flow in the airways reduces toward the periphery. This also means that convective forces dominate in gas transport in proximal airways, whereas diffusive forces dominate in the small airways down to a semistationary front that makes gas mixing by diffusion possible. In HMD, the pathologic process is mainly confined to the distal airways, e.g. respiratory bronchioles and alveolar ducts, with presence of epithelial sloughs, hyaline membrane formation, marked decrease in alveolar volume, and interstitial edema (23). The consequence of this disease process must lead to changes in the boundary conditions of the interface between the inspired gas front and the remaining alveolar gas due partly to reduction of the total cross-sectional area, where the diffusive gas mixing is supposed to take place. The functional implication upon ventilation by this condition is a reduction of that part of the tidal breath $\left(V_{T}-V_{D}\right)$ mixing with the alveolar gas. In our study, control animals had a significantly lower effective breath fraction $\left[\left(\mathrm{V}_{\mathrm{T}}-\mathrm{V}_{\mathrm{D}}\right) / \mathrm{V}_{\mathrm{T}}\right]$ compared with the surfactant-treated group. Patency of the peripheral airways in the lung seems to be essential for establishment of an adequate gas mixing and alveolar ventilation. Previous histologic studies have also shown that surfactant plays an important role in maintaining patency of the distal airways during breathing $(13,28)$.

The NC index, as used in this study, is an efficiency index reflecting the efficiency of gas mixing in peripheral airways (19, 20). The index consists of the ratio of the accumulated ventilatory volume and the total lung volume (FRC). This ratio, often called "turnovers" in previous studies, is a common normalization of the washout curve. In our study, the NC index indicates the number of turnovers necessary to dilute the total lung nitrogen volume from 90 to $10 \%$. The more efficient the lung is in mixing inspired gas with remaining alveolar gas in the distal airways, the less ventilation is required to dilute the lung nitrogen, and the NC index becomes low. In our study, the NC index was significantly lower in surfactant-treated animals compared with the control group, indicating an improved ventilatory efficiency and improved gas mixing in the surfactant-treated animals.

In the analysis of the nitrogen elimination curves in our study, a single exponential washout pattern dominated in both the surfactant-treated and control groups, with no significant differences between the groups (Table 1). This means that an even distribution of ventilation should dominate in both groups, although parallel gas inhomogeneity with multiple exponential washout pattern could be expected in the lungs with HMD, which has been found by other investigators $(29,30)$. The application of PEEP probably concealed possible gas inhomogeneity in our control group (31-33). It might also be possible that our analysis of the washout pattern in a linear instead of a semilogarithmic fashion could disregard very slowly ventilated compartments. Also, there is the possibility that, by extending the washout course to very low nitrogen concentration values beyond the end tidal concentration of $2 \%$, we could have detected slowly ventilated compartments of the lung. However, the analysis of the multiple breath nitrogen washout course in terms of separate exponential curves representing separate lung compartments has been questioned $(26,34)$. Model analysis has revealed a complex interaction between convective and diffusive forces in gas mixing during breathing, making predictions about lung compartments due to disease processes difficult (26). The fact that the predictions are based on gas concentration analysis at the mouth, far from the distal airways, further complicates this concept.

The utmost effect of surfactant in the lung is to reduce the 


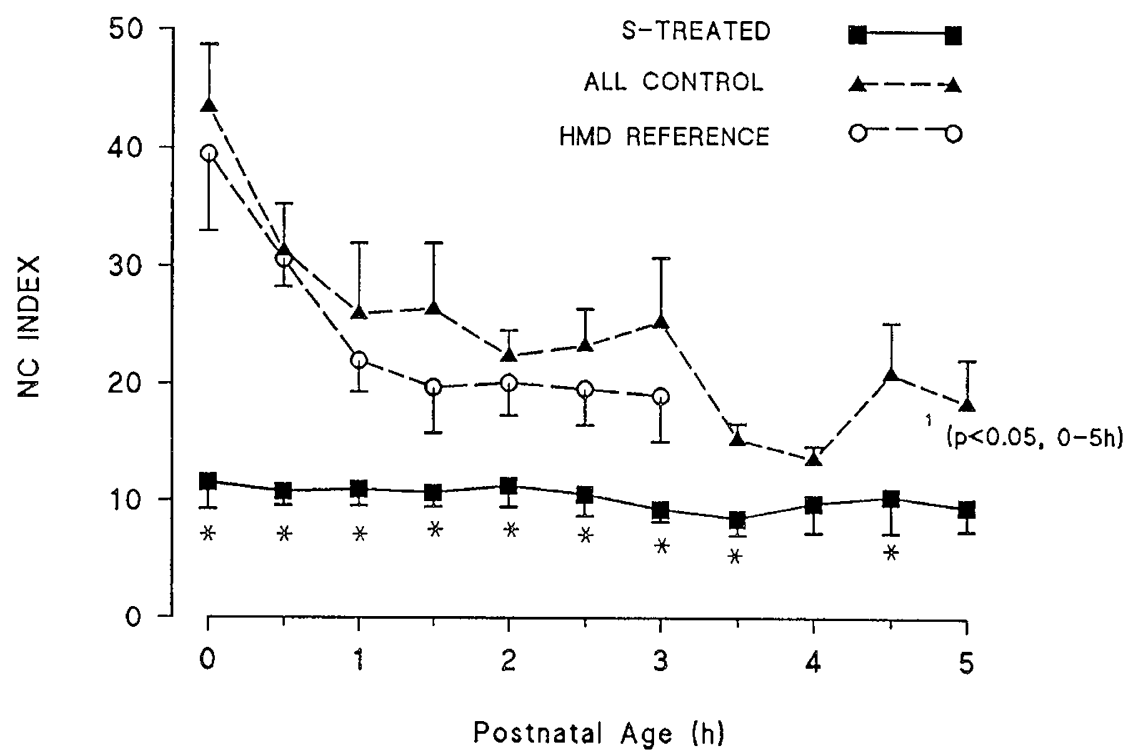

Fig. 7. NC index during the study. For statistical abbreviations, see legend for Figure 2.

Table 1. Component analysis of the nitrogen elimination pattern (distribution of ventilation)

\begin{tabular}{lccccc}
\hline & & \multicolumn{5}{c}{ Components $\dagger$} \\
\cline { 3 - 6 } & $n^{*}$ & One & Two & Three & Other \\
\hline Surfactant treated & 80 & $61(76.3)$ & $15(18.8)$ & 0 & $4(5.0)$ \\
All controls & 69 & $56(81.2)$ & $9(13.0)$ & 0 & $4(5.8)$ \\
HMD reference & 34 & $25(73.5)$ & $7(20.6)$ & 0 & $2(5.9)$ \\
\hline
\end{tabular}

$* n=$ number of washout curves during the whole study.

$\uparrow$ Numbers in parentheses indicate percentages.

surface tension in the air-liquid interface. In animal studies, several investigators have shown an improvement in $\mathrm{C}_{\mathrm{dyn}}$ after surfactant treatment in immature lung disease (4-8). In our study, there were also differences in $C_{d y n}$ between surfactanttreated and untreated animals, with significantly higher $\mathrm{C}_{\mathrm{dyn}}$ in the treated group. Surfactant, however, did not completely normalize $C_{d y n}$ in the treatment group when compared with values obtained in full-term healthy lambs (35). Because the pressurevolume relationship of the lung is not a linear function, and because $C_{d y n}$ also is a function of the lung volume, changes in $\mathrm{C}_{\mathrm{dyn}}$ have to be interpreted in relation to the actual FRC. In our study, we found no significant differences in specific compliance $\left(\mathrm{C}_{\mathrm{dyn}} / \mathrm{FRC}\right)$ between the treated and untreated animals during the 1st hour of life (Fig. 6B). The difference in lung volume during this time could explain the improvement in $C_{d y n}$ in the surfactant-treated group. After $1 \mathrm{~h}$ of age, however, specific compliance was lower in the untreated group, indicating higher surface tension. This difference was, however, not statistically significant, which might be partly due to the fact that only a few control animals could be studied later during the study because of the presence of a pneumothorax. The lack of significant improvement in $\mathrm{C}_{\mathrm{dyn}}$ after surfactant treatment previously found during mechanical ventilation in some studies, both in animals (2) and in infants (1), could be explained by a concomitant increase in FRC. In this case, the lung might be ventilated at the upper part of an assumed S-shaped pressure-volume curve, where $\mathrm{C}_{\mathrm{dyn}}$ is lower. These studies further indicate the importance of simultaneous measurements of lung mechanics and lung volume in the evaluation of the mechanical impact on lung function by surfactant treatment. The possible influence of PEEP on FRC and lung mechanics must also be considered.

In summary, surfactant-pretreated lambs delivered prematurely at 129 to $131 \mathrm{~d}$ of gestation did not develop histologic HMD and showed significant inmprovement in gas mixing abil- ity between inspired and remaining gas in the distal airways in the lung. We speculate that the main functional effect of surfactant treatment is to maintain the patency of the peripheral airways and alveoli in the lung. This facilitates the diffusive gas mixing process with improvement in $\dot{V}_{\mathrm{A}}$ and gas exchange. Surfactant treatment also reduced the ventilatory support, had impact on lung mechanics, and established an adequate FRC earlier after birth.

We also speculate that surfactant prevents therapy-induced overexpansion of conducting airways, which could be hazardous for the development of chronic lung disease in infancy.

Acknowledgments. The authors thank Dr. Mary Phillips Gray for reviewing the pulmonary histology; Dr. Mildred T. Stahlman for her support and advice; Robert Parker, Ph.D., for statistical help; Patricia Minton, R.N., Stanley Poole, and Rao Gaddipati for their skilled technical assistance; and Jackie Dawson for typing the manuscript. Computer programs for lung function studies were kindly provided by The Foundation for Biomedical Engineering, Chalmers University of Technology, Gothenburg, Sweden.

\section{REFERENCES}

1. Davis J, Veness-Meehan K, Notter R, Bhutani V, Kendig J, Shapiro D 1988 Changes in pulmonary mechanics after the administration of surfactant to infants with respiratory distress syndrome. N Engl J Med 319:476-479

2. Durand D, Clyman R, Heymann M, Clements J, Mauray F, Kitterman J, Ballard P 1985 Effects of protein-free, synthetic surfactant on survival and pulmonary function in preterm lambs. J Pediatr 107:775-780

3. Egan E, Notter R, Kwong M, Shapiro D 1983 Natural and artificial lung surfactant therapy in premature lambs. J Appl Physiol 55:875-883

4. Jacobs H, Jobe A, Ikegami M, Glatz T, Jones S, Barajas L 1982 Premature lambs rescued from respiratory failure with natural surfactant: clinical and biophysical correlates. Pediatr Res 16:424-429

5. Jobe A, Ikegami M, Glatz T, Yoshida Y, Diakomanolis E, Padbury J 1981 Duration and characteristics of treatment of premature lambs with natural surfactant. J Clin Invest 67:370-375

6. Lachmann B, Grossmann G, Nilsson R, Robertson B 1981 Effect of supplementary surfactant on in vivo lung mechanics in the premature rabbit neonate. Eur J Pediatr 136:173-179

7. Tooley W, Clements J, Muramatsu K, Brown C, Schlueter M 1987 Lung function in prematurely delivered rabbits treated with synthetic surfactant. Am Rev Respir Dis 136:651-656

8. Vidyasagar D, Maeta H, Raju T, John E, Bhat R, Go M, Dahiya U, Roberson Y, Yamin A, Narula A, Evans M 1985 Bovine surfactant (Surfactant TA) therapy in immature baboons with hyaline membrane disease. Pediatrics 75:1132-1142

9. Enhorning G, Shennan A, Possmayer F, Dunn M, Chen C, Milligan J 1985 Prevention of neonatal respiratory distress syndrome by tracheal instillation of surfactant: a randomized clinical trial. Pediatrics 76:145-153 
10. Fujiwara T, Chida S, Watabe $Y$, Maeta H, Morita T, Abe T 1980 Artificial surfactant therapy in hyaline membrane disease. Lancet 12:55-59

11. Merritt A, Hallman M, Bloom B, Berry C, Benirschke K, Sahn D, Key T, Edwards D, Jarvenpaa A, Pohjavouri M, Kankaanpaa K, Kunnas M, Paatero H, Rapola J, Jaaskelainen J 1986 Prophylactic treatment of premature infants with human surfactant. N Engl J Med 315:785-790

12. Maeta H, Vidyasagar D, Raju T, Bhat R, Matsuda H 1988 Early and late surfactant treatment in baboon model of hyaline membrane disease. Pediatrics $81: 277-283$

13. Nilsson R, Grossmann G, Robertson B 1978 Lung surfactant and the pathogenesis of neonatal bronchiolar lesions induced by artificial ventilation. Pediatr Res 12:249-255

14. Jobe A, Ikegami M 1984 The prematurely delivered lamb as a model for studies of neonatal adaptation. In: Nathanielsz PW (ed) Animal Models in Fetal Medicine. Perinatology Press, Ithaca, NY, pp 1-30

15. Albert R, Keighley G 1974 The arterial/alveolar oxygen tension ratio. An index of gas exchange applicable to varying inspired oxygen concentrations. Am Rev Respir Dis 109:142

16. Sandberg K, Sjoqvist B, Hjalmarson O, Olsson T 1987 Lung function in newborn infants with tachypnea of unknown cause. Pediatr Res 22:581-586

17. Sjoqvist B, Sandberg K, Hjalmarson O, Olsson T 1984 Calculation of lung volume in newborn infants by means of a computer assisted nitrogen washout method. Pediatr Res 18:1160-1164

18. Sjoqvist B, Sandberg K, Hjalmarson O, Olsson T 1986 Method for analyzing multiple-breath nitrogen washouts. Med Biol Eng Comput 24:83-90

19. Cumming G 1967 Gas mixing efficiency in the human lung. Respir Physio 2:213-224

20. Sandberg K, Sjoqvist B, Hjalmarson O, Olsson T 1987 Efficiency of ventilation in neonatal pulmonary maladaptation. Acta Paediatr Scand 76:30-36

21. Mead J, Milic-Emili J 1964 Handbook of Physiology, Respiration. American Physiological Society, Williams and Wilkins, Baltimore, pp 363-376

22. Hjalmarson O 1974 Mechanics of breathing in newborn infants with pulmonary disease. Acta Paediatr Scand [Suppl] 247:5-70
23. Stahlman M, LeQuire V, Young W, Merrill R, Birmingham R, Payne G, Gray J 1964 Pathophysiology of respiratory distress in newborn lambs. Am J Dis Child 108:375-393

24. Shaffer T, Koen P, Moskowitz G, Ferguson J, Delivoria-Papadopoulos M 1978 Positive end expiratory pressure: effects on lung mechanics of premature lambs. Biol Neonate 34:1-10

25. O'Brodovich H, Mellins R 1985 Bronchopulmonary dysplasia. Unresolved neonatal acute lung injury. Am Rev Respir Dis 132:694-709

26. Engel L 1983 Gas mixing within the acinus of the lung. J Appl Physiol 54:609618

27. Paiva M, Engel L 1987 Theoretical studies of gas mixing and ventilatory distribution in the lung. Physiol Rev 67:750-796

28. Macklem P, Proctor D, Hogg J 1970 The stability of peripheral airways. Respir Physiol 8:191-203

29. Corbet AJS, Ross JA, Beaudry PH, Stern L 1974 Ventilation-respiration relationship as assessed by a $\mathrm{ADN}_{2}$ in hyaline membrane disease. J Appl Physiol 36:74-81

30. Richardson P, Jarriel S, Hansen T 1989 Mechanics of the respiratory system during passive exhalation in preterm lambs. Pediatr Res 26:425-428

31. Corbet AJS, Ross JA, Beaudry PH, Stern L 1975 Effect of positive-pressure breathing on a $\mathrm{ADN}_{2}$ in hyaline membrane disease. J Appl Physiol 38:3338

32. Richardson CP, Jung AL 1978 Effects of continuous positive airway pressure on pulmonary function and blood gases of infants with respiratory distres syndrome. Pediatr Res 12:771-774

33. Jarriel S, Richardson P Pace R, Valdes E, Hansen T 1989 Positive endexpiratory pressure (PEEP) reduces ventilation inhomogeneities in hyaline membrane disease in lambs. Pediatr Res 25:314A(abstr)

34. Bowes C, Richardson J, Cumming G, Horsefield K 1985 Effect of breathing pattern on gas mixing in a model with asymmetrical alveolar ducts. $J$ App Physiol 58:18-26

35. Sandberg K, Englehardt B, Hellerqvist C, Sundell H 1987 Pulmonary response to group B streptococcal toxin in young lambs. J Appl Physiol 63:20242030 